\title{
Pharmaceuticals Benefit Scheme: Effects of the Safety Net
}

\section{Laurie Brown, Annie Abello and Ann Harding}

$\mathrm{T}$ The aim of the Australian Pharmaceuticals Benefit Scheme (PBS) is to provide Australians with affordable, reliable and timely access to necessary and cost-effective medicines (Department of Health and Ageing, 2005). The Australian PBS has two key policy settings: patient copayments and the 'safety net' (SN). The copayment is the direct out-of-pocket contribution the patient has to pay towards the cost of their medicine — for some drug items, consumers may also have to pay a brand or therapeutic price premium. The PBS SN arrangements 'protect' individuals and families from large overall expenses incurred through high use of PBS medicines within a calendar year. The basic objective of the SN is to cap PBS drug costs to the 'sick' that is, to high users. Its operation is only means tested in the sense that two thresholds exist - a lower threshold for concessional patients and a higher threshold for general patients. Individuals and families who are eligible to access PBS medicines at reduced concessional copayment and SN rates are those who have low incomes and/or are recipients of certain Commonwealth Government pensions and allowances. For concessional patients, the SN threshold has traditionally been set at 52 PBS scripts per year. Once these patients reach the SN, they are no longer required to pay the patient copayment for PBS subsidised items for the remainder of the year. For general patients reaching the $\mathrm{SN}$, the copayment rate is reduced to the lower concessional rate. In his 2005 budget speech, the Federal Treasurer, the Hon. Peter Costello, announced that the SN thresholds would increase for both concessional and general patients from 1 January 2006.

Within this policy context, this paper investigates which Australian families are likely to be high users of PBS medicines and therefore benefit from the PBS safety net arrangements. The proportion of PBS scripts used by concessional and general patients funded under the $\mathrm{SN}$ arrangements is examined and the distribution of scripts and costs across different family types investigated. Previous research has shown that the PBS is highly progressive with major redistributive effects towards the poor (Harding et al, 2004). The benefits of the SN are available to all heavy users of PBS scripts, irrespective of income within each of the concessional and general patient categories. The SN is not primarily an instrument of redistribution but it may have an incidental redistributive effect because the poor generally have lower health status and are relatively high users of PBS medicines (Harding et al, 2004; AIHW, 2006). A secondary aim of the

Laurie Brown is Associate Professor and Research Director (Health), Annie Abello is a Senior Research Fellow, and Ann Harding is Professor and Director of the National Centre for Social and Economic Modelling, University of Canberra. 
paper, therefore, is to identify which Australian families are likely to be impacted by this latest change to the PBS rules and what implications this might have in terms of the PBS acting as a form of indirect social cash transfer.

A microsimulation model of the PBS, known as 'MediSim', is used to investigate the use of PBS medicines by different types of families and consumer and government expenditures. The 2005-06 financial year is simulated under prebudget PBS settings that is, in the absence of the increase in SN thresholds but including annual CPI indexation. A short overview of the policy background is provided in the following section. The MediSim modelling and methods are then described briefly. Results are presented in terms of the simulated PBS outlays and script use by income quintile and family type-lifecycle group. The paper concludes with some comments on the importance of the $\mathrm{SN}$ in protecting Australian families from 'large' out-of-pocket expenditures on PBS medicines and implications of the policy change to increase SN thresholds.

\section{Policy Background}

In 2004-05, Commonwealth Government expenditure on the PBS was $\$ 5.6$ billion or 15 per cent of total Government health expenditure. Historically, government expenditure on the PBS has grown nominally by more than 10 per cent per annum, well above growth in the total health budget or in GDP. Over the next couple of years, increases in government spending on the PBS are expected to be below the long run average growth of the PBS with a projected increase of 5.4 per cent per annum in real terms compared to 3.3 per cent for the total health budget (Department of Treasury, 2005). However, the Government's share of the costs of the PBS has steadily increased over time as PBS policy settings, which largely determine patient contributions, have increased in general only in line with inflation. Currently, the government subsidises patients to the extent of over 80 per cent of total PBS drug costs, with 80 per cent of government outlays going to concessional patients (Brown et al, 2004; Harding et al, 2004).

Patient copayments and SN thresholds are indexed to movements in the CPI from 1 January each year. However, these two policy settings have been the focus of recent budgetary measures aimed at curtailing government expenditure by shifting costs back to consumers. From 1 January 2005, patient copayments increased by 21 per cent as a result of a 2002 proposed federal budget measure that was passed by the Senate in mid-2004 after a 'back-flip' by the federal Labour Party (Harvey, 2005). With this policy change, SN arrangements were 'untouched' in that they increased proportionately with the rise in copayments. However, in the 2005-06 federal budget, the Treasurer announced that the number of prescriptions concessional families would need to reach the SN threshold would increase from 1 January 2006 from the current 52 scripts by two prescriptions each year up to and including 1 January 2009. For general patients, the SN threshold would increase from the current level by the dollar equivalent of two copayments each year from 1 January 2006 to 1 January 2009. The existing annual indexation of the SN thresholds would continue to be applied on top of these increases. 
It was estimated that this measure would generate savings to Government of only $\$ 1.7$ million in 2005-06 but would increase to over $\$ 71.4$ million by 2008-09, representing approximately a one per cent saving in expected Government expenditure in 2008-09. Changes to the SN threshold were viewed by Government as 'helping to maintain the sustainability of the PBS' (Department of Treasury, 2005a).

The cost of medicines whose price fall below the patient copayment levels (known as below-copay medicines) is fully borne by the patient. The cost of below-copay drugs is included in patients' contribution towards the SN. However, the cost of non-PBS listed prescribed medicines (private medicines) is not counted towards the PBS SN. The same concessional or general SN threshold is applied to a family unit whether the unit consists of a single individual, a couple or a family with dependent children. Each family's SN threshold is reset to zero at 1 January each year. The changes in the policy settings are given in Table 1 alongside those used in the modelling.

Table 1: Pharmaceutical Benefits Scheme: Policy Settings 2005-06

\begin{tabular}{l|rrr}
\hline & $1 / 1 / 2005^{a}$ & $\begin{array}{c}1 / 1 / 2006^{a} \\
\text { (after policy change) } \\
\text { dollars }\end{array}$ \\
& \multicolumn{3}{c}{$\begin{array}{c}1 / 1 / 2006^{p} \\
\text { (without policy change) }\end{array}$} \\
\hline Copayment: Concessional & 4.60 & 4.70 & 4.72 \\
Below safety net & 0 & 0 & 0 \\
Above safety net & & & 29.34 \\
Copayment: General & 28.60 & 29.50 & 4.72 \\
Below safety net & 4.60 & 4.70 & 245.42 \\
Above safety net & 239.20 & 253.80 & 897.65 \\
Safety net: Concessional & 874.90 & 960.10 & \\
Safety net: General & & & \\
\hline
\end{tabular}

Note: $\mathrm{a}=$ actual; $\mathrm{p}=$ projected from previous year using CPI growth estimate of 2.6 per cent.

Source: Department of Health and Ageing (2006)

\section{Methods}

Modelling the PBS with 'MediSim'

Microsimulation modelling was used in this study as this technique brings a range of benefits to policy analysis: model databases can mirror the heterogeneity in the population as revealed in large national household surveys; models can replicate the complexity of the policy structures, transfers, and settings under investigation; they can be used to forecast the outcomes of policy changes and to examine the effects of policy changes for narrowly defined groups of individuals, with model estimates providing insight into the distributional impacts of a policy for which 
'real' data are not otherwise available (Creedy, 2001; Brown and Harding, 2002; Brown and Harding, 2005).

MediSim is designed to simulate current and future use and costs of PBS-subsidised medicines, under existing PBS and different policy settings, and the distributional effects of policy changes estimated (see for example Brown et al, 2003; Brown et al, 2004; Harding et al, 2004). The primary utility of the model is its capability to generate government PBS outlays and consumer costs based on various script volume, drug price, patient copayment and safety net assumptions, as well as to estimate the corresponding effects on families belonging to various income and household groups. The conceptual and technical constructs of MediSim are described in detail elsewhere (Abello et al, 2003; Brown et al, 2004; Brown and Harding, 2005; Lymer and Brown, 2006; Abello et al, 2006). MediSim's base dataset comprises a statistically matched ABS National Health Survey (2001) Basic Confidentialised Unit Record File (CURF) with a modified 1998-99 Household Expenditure Survey Basic CURF and various Medicare Australia (formerly Health Insurance Commission) aggregated data sets on PBS script volumes, costs and settings. The statistical matching allowed the creation of synthetic families (ABS NATSEM Technical Working Group, 2004; Abello et al, 2006). As the PBS SN operates at the income unit level, complete information on all family or income unit members' drug usage and expenditure is needed to adequately model this component of the PBS.

The imputation of drug usage is such that scripts in the model's base year (currently 2003-04) match actual data on total scripts by drug class and the distribution of scripts per person, by concession card status, gender and age group. The PBS is modelled by applying the rules of the scheme to each individual and family in the dataset over an 18-month period on a monthly basis, starting on 1 January. To generate out-years - as used in this study - the base population is 'aged' and the script and cost data in the person-level dataset revised each year according to pharmaceutical trends. MediSim generates cost estimates based on a distributional approach to drug pricing to reflect variation existing in prices within each drug class. Consumer costs are derived from patient copayment rates and script volumes and do not include brand or therapeutic price premiums.

\section{Analyses}

Individuals and families reaching the $\mathrm{SN}$, for both concessional and general groups, were identified in the model and their script volumes and costs calculated. Differences by income quintile and selected family type-lifecycle group are reported here (for other breakdowns, see Brown, Abello and Harding, 2005). The new OECD equivalence scale was used to derive income quintile from equivalent disposable annual family income and was calculated separately for concessional and general patients. Family type-lifecycle group is defined in terms of whether or not there are dependent children in the family, whether or not there are one or two adults in the family group, plus age of the head of the family (ABS, 2001). 
The results apply only to families identified in the model as using PBS medicines in the 2005-06 outyear. Of the 3.91 million families with concessional status in the model, representing a total population of 6.91 million persons, nearly all families and individuals used PBS medicines (98 per cent and 94 per cent respectively). For the 6.44 million families without concessional entitlements, only 40 per cent of families were identified as PBS-users. Because many of these 'families' are sole person income units, only 24 per cent of all general patients in MediSim were identified as using PBS medicines in the 12-month simulation.

\section{Estimated Script Volumes and Costs}

MediSim predicted 171.6 million scripts would be subsidised under the PBS at a total cost of \$6.6 billion if PBS settings remained unchanged in 2005-06 (apart from the normal CPI indexation) (Table 2). Government provides 82 per cent of the total expenditure. Nearly 90 per cent of the costs of the 143.6 million scripts used by concessional families are met by the Government but only 62 per cent of the cost of the 28.1 million scripts used by general patients. Of all scripts used by concessional families, 24 per cent reach the SN compared with 20 per cent for non-concessional families. Concessional families reaching the concessional SN received 61 per cent of total government outlays for all concessional families. The SN reduced these families' out-of-pocket costs by $\$ 159.7$ million (average copayment 'multiplied by' above-SN scripts). This is equivalent to two-thirds of the estimated contribution these families make to the cost of their PBS medicines. The SN effectively reduces the average script cost for concessional families from $\$ 4.64$ for non-SN households to \$2.82 for SN households.

Table 2: MediSim Estimates of PBS Scripts and Costs, 2005-06

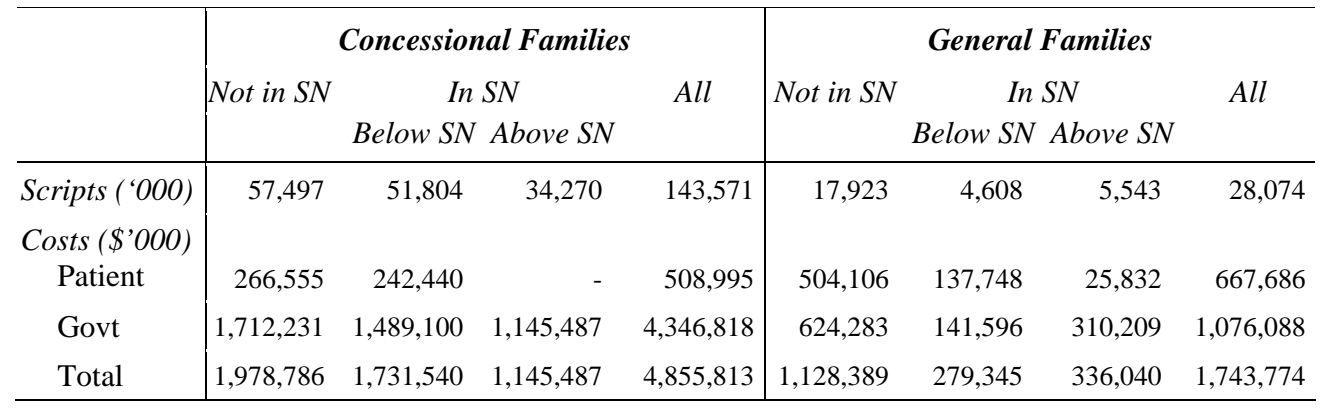

Families without concessional status reaching the general patient SN received 42 per cent of government outlays on scripts for non-concessional families. The SN saved general patients \$160.6 million which nearly matched these families' direct contributions to costs. The SN effectively reduced the average script cost for general families from over $\$ 28.00$ for non-SN households to $\$ 16.11$ for SN families. General patient families reaching the SN also benefit from the Government 'picking up the tab' for any below copay medicines whose price falls between the general copayment and the concessional copayment that they pay 
over the remainder of the year. The size of this subsidisation is unknown. But which Australian families are reaching the SN and benefiting from increased government subsidisation?

\section{Distributional Impacts of the PBS Safety Net}

\section{Income quintile}

The SN may be interpreted as distribution neutral if the income distribution of SN families is the same as the income distribution of non-SN families. The distribution of SN and non-SN families is similar for the general population but, for the concessional population, the SN appears to be non-neutral with a skew toward the second-bottom and middle quintiles (Table 3). For example, 33 per cent of the second poorest and 44 per cent of middle income quintile concessional families reach the SN in the modelling. These families receive the greatest share of all government expenditure on the PBS (13.2 per cent and 11.5 percent of government outlays respectively). However, in terms of Government subsidisation as a proportion of family annual disposable income then Government outlays are most important for the poorest 40 per cent of concessional families who reach the SN - the government subsidy they receive on their PBS medicines is equivalent to $17-18$ per cent of their family income. This is important because family spending on PBS subsidised medicines per year is on average 2.5 times higher for families reaching the SN than families not reaching the SN. This occurs for both families with and without concessional status.

For non-concessional families, approximately 11 per cent of families in each income quintile reach the SN. In Table 3, family expenditure per year on PBS medicines for non-concessional families reaching the $\mathrm{SN}$ is below the $\mathrm{SN}$ threshold given in Table 1 for general patients. This gap reflects the 'unknown' out-of-pocket expenditure on below copay drugs which contributes to a family's overall expenditure permissible under the SN arrangements.

\section{Family type-lifecycle group}

Table 4 presents the modelling results for selected types of families. The proportion of families reaching the SN threshold varies substantially across these groups. Very few sole parent families, irrespective of concessional status, benefit from the SN arrangements. For those sole parent families reaching the SN, the Government outlay on their PBS medicines is important when seen as a proportion of annual family disposable income. For concessional families, only 18 per cent of couples with children are expected to reach the SN compared with 28 per cent of older single persons and 67 per cent of older couples without children. In comparison, for general patient families, 10 per cent of 'couples with children' families will reach the SN, 23 per cent of older single persons and 43 per cent of older couples without children. Young singles and couples do not generally reach SN thresholds whether or not they are concession cardholders (only 1-2 per cent of these families reach SN levels of PBS medicine use). 
Table 3: Estimated Impact of the PBS by Income Quintile, 2005-06 (for PBS users)

\begin{tabular}{|c|c|c|c|c|c|c|c|c|c|c|c|c|c|c|}
\hline & & & \multicolumn{6}{|c|}{ Families not reaching SN } & \multicolumn{6}{|c|}{ Families reaching $S N$} \\
\hline & & & Bottom & Next $20 \%$ & Middle & Next $20 \%$ & Tор & All & Bottom & Next $20 \%$ & Middle & Next $20 \%$ & Top & All \\
\hline \multicolumn{2}{|l|}{ Concessional } & Unit & & & & & & & & & & & & \\
\hline Disposable annual income per family & (1) & $\$$ & 12,183 & 15,989 & 25,815 & 27,934 & 33,297 & 23,427 & 12,786 & 17,988 & 25,028 & 27,582 & 39,395 & 24,413 \\
\hline Family spending per year on PBS drugs & (2) & $\$$ & 94 & 103 & 119 & 100 & 85 & 97 & 246 & 246 & 246 & 246 & 246 & 246 \\
\hline Family spending as proportion of income & $(1 / 2)$ & $\%$ & 0.8 & 0.6 & 0.5 & 0.4 & 0.3 & 0.4 & 1.9 & 1.4 & 1.0 & 0.9 & 0.6 & 1.0 \\
\hline Govt subsidy on PBS drugs/family/year & (3) & $\$$ & 602 & 723 & 752 & 670 & 561 & 640 & 2312 & 3056 & 2873 & 2611 & 2646 & 2732 \\
\hline Govt subsidy as proportion of income & $(3 / 1)$ & $\%$ & 4.9 & 4.5 & 2.9 & 2.4 & 1.7 & 2.7 & 18.1 & 17.0 & 11.5 & 9.5 & 6.7 & 11.2 \\
\hline \multicolumn{2}{|c|}{$\%$ of all PBS govt subsidy received by this group } & $\%$ & 7.4 & 6.3 & 4.2 & 5.8 & 7.9 & 31.6 & 7.4 & 13.2 & 11.5 & 8.1 & 8.4 & 48.6 \\
\hline \multicolumn{2}{|c|}{ No. of families ('000) } & no. & 678 & 494 & 283 & 558 & 821 & 2,834 & 173 & 248 & 213 & 170 & 195 & 998 \\
\hline \multicolumn{2}{|l|}{ Proportion of families in quintile } & $\%$ & 79.7 & 66.6 & 57.1 & 76.6 & 80.8 & 74.0 & 20.3 & 33.4 & 42.9 & 23.4 & 19.2 & 26.0 \\
\hline \multicolumn{2}{|l|}{ No. of persons ('000) } & no. & 1,014 & 847 & 807 & 994 & 1,033 & 4,696 & 284 & 488 & 463 & 301 & 270 & 1,807 \\
\hline \multicolumn{2}{|l|}{ Proportion of persons in quintile } & $\%$ & 78.1 & 63.4 & 63.5 & 76.8 & 79.3 & 72.2 & 21.9 & 36.6 & 36.5 & 23.2 & 20.7 & 27.8 \\
\hline \multicolumn{15}{|l|}{ General } \\
\hline Disposable annual income per family & (1) & $\$$ & 27,694 & 38,469 & 44,283 & 58,130 & 89,800 & 54,721 & 25,551 & 37,479 & 47,700 & 62,013 & 92,641 & 56,296 \\
\hline Family spending per year on PBS drugs & (2) & $\$$ & 278 & 283 & 261 & 249 & 283 & 271 & 715 & 706 & 726 & 669 & 745 & 714 \\
\hline Family spending as proportion of income & $(1 / 2)$ & $\%$ & 1.0 & 0.7 & 0.6 & 0.4 & 0.3 & 0.5 & 2.8 & 1.9 & 1.5 & 1.1 & 0.8 & 1.3 \\
\hline Govt subsidy on PBS drugs/family/year & (3) & $\$$ & 337 & 372 & 306 & 311 & 370 & 341 & 1987 & 1898 & 2266 & 1666 & 2102 & 1983 \\
\hline Govt subsidy as proportion of income & $(3 / 1)$ & $\%$ & 1.2 & 1.0 & 0.7 & 0.5 & 0.4 & 0.6 & 7.8 & 5.1 & 4.8 & 2.7 & 2.3 & 3.5 \\
\hline \multicolumn{2}{|c|}{$\%$ of all PBS govt subsidy received by this group } & $\%$ & 2.0 & 2.6 & 2.0 & 2.0 & 2.9 & 11.5 & 1.7 & 1.9 & 1.4 & 1.3 & 2.1 & 8.3 \\
\hline \multicolumn{2}{|l|}{ No. of families ('000) } & no. & 344 & 468 & 431 & 477 & 564 & 2,283 & 48 & 64 & 46 & 53 & 76 & 288 \\
\hline \multicolumn{2}{|l|}{ Proportion of families in quintile } & $\%$ & 87.8 & 88.0 & 90.4 & 90.0 & 88.1 & 88.8 & 12.2 & 12.0 & 9.6 & 10.0 & 11.9 & 11.2 \\
\hline \multicolumn{2}{|l|}{ No. of persons ('000) } & no. & 528 & 605 & 531 & 556 & 619 & 2,838 & 110 & 115 & 79 & 90 & 111 & 505 \\
\hline \multicolumn{2}{|l|}{ Proportion of persons in quintile } & $\%$ & 82.8 & 84.0 & 87.0 & 86.1 & 84.8 & 84.9 & 17.2 & 16.0 & 13.0 & 13.9 & 15.2 & 15.1 \\
\hline
\end{tabular}


Table 4: Estimated Impact of the PBS by Family Type, 2005-06 (PBS Users)

\begin{tabular}{|c|c|c|c|c|c|c|c|c|c|c|c|c|c|c|c|c|}
\hline & \multicolumn{7}{|c|}{ Families Not Reaching SN } & \multicolumn{7}{|c|}{ Families Reaching SN } \\
\hline & & & $\begin{array}{l}\text { Couples } \\
\text { with } \\
\text { children }\end{array}$ & $\begin{array}{c}\text { Sole } \\
\text { parent }\end{array}$ & $\begin{array}{c}\text { Couple } \\
\text { only, head } \\
<35 y r s\end{array}$ & $\begin{array}{c}\text { Couple } \\
\text { only, head } \\
65+\text { yrs }\end{array}$ & $\begin{array}{l}\text { Single } \\
\text { Person } \\
<35 y \text { rs } \\
\end{array}$ & $\begin{array}{l}\text { Single } \\
\text { person } \\
65+\text { yrs }\end{array}$ & All & $\begin{array}{l}\text { Couples } \\
\text { with } \\
\text { children }\end{array}$ & $\begin{array}{c}\text { Sole } \\
\text { parent }\end{array}$ & $\begin{array}{c}\text { Couple } \\
\text { only, head } \\
<35 y r s\end{array}$ & $\begin{array}{c}\text { Couple } \\
\text { only, head } \\
65+\text { yrs }\end{array}$ & $\begin{array}{l}\text { Single } \\
\text { Person } \\
<35 y r s\end{array}$ & $\begin{array}{c}\text { Single } \\
\text { person } \\
65+y r s \\
\end{array}$ & All \\
\hline Disposable annual income per family & (1) & $\$$ & 36,570 & 29,456 & 30,027 & 27,754 & 19,865 & 17,773 & 23,427 & 39,867 & 27,013 & 38,350 & 26,733 & 19,255 & 17,490 & 24,413 \\
\hline Family spending per year on PBS drugs & (2) & $\$$ & 113 & 70 & 60 & 165 & 30 & 124 & 97 & 247 & 248 & 246 & 246 & 250 & 245 & 246 \\
\hline $\begin{array}{l}\text { Family spending as proportion of income } \\
(2 / 1)\end{array}$ & & $\%$ & 0.3 & 0.2 & 0.2 & 0.6 & 0.2 & 0.7 & 0.4 & 0.6 & 0.9 & 0.6 & 0.9 & 1.0 & 1.0 & 1.0 \\
\hline $\begin{array}{l}\% \text { of all PBS Govt subsidy received by this } \\
\text { group }\end{array}$ & & $\%$ & 4.0 & 2.4 & 0.3 & 4.2 & 1.7 & 10.1 & 31.6 & 3.3 & 0.3 & 0.04 & 25.0 & 0.2 & 10.6 & 48.6 \\
\hline No. of families ('O00) & & '000 & 349 & 359 & 38 & 224 & 481 & 670 & 2,834 & 74 & 11 & 1 & 455 & 5 & 261 & 998 \\
\hline Proportion of persons in quintile & & $\%$ & 82.5 & 97.0 & 97.4 & 33.0 & 99.0 & 72.0 & 74.0 & 17.5 & 3.0 & 2.6 & 67.0 & 1.0 & 28.0 & 26.0 \\
\hline \multicolumn{17}{|l|}{ General } \\
\hline Disposable annual income per family & (1) & $\$$ & 69,975 & 54,095 & 58,683 & 52,116 & 30,626 & 33,177 & 54,721 & 72,637 & 60,587 & 65,869 & 51,387 & 29,710 & 30,692 & 56,296 \\
\hline Govt subsidy as proportion of income & $(3 / 1)$ & $\%$ & 0.5 & 0.9 & 0.3 & 1.2 & 0.5 & 0.8 & 0.6 & 2.6 & 4.1 & 1.7 & 6.8 & 3.9 & 5.5 & 3.5 \\
\hline $\begin{array}{l}\% \text { of all PBS Govt subsidy received by this } \\
\text { group }\end{array}$ & & $\%$ & 4.7 & 0.4 & 0.2 & 0.5 & 0.7 & 0.1 & 11.5 & 2.9 & 0.1 & 0.03 & 1.6 & 0.1 & 0.3 & 8.3 \\
\hline No. of families ('000) & & '000 & 991 & 44 & 109 & 44 & 219 & 30 & 2,283 & 115 & 2 & 2 & 33 & 4 & 9 & 288 \\
\hline Proportion of persons in quintile & & $\%$ & 89.6 & 95.7 & 98.2 & 57.1 & 98.2 & 76.9 & 88.8 & 10.4 & 4.3 & 1.8 & 42.9 & 1.8 & 23.1 & 11.2 \\
\hline
\end{tabular}


'Couples only with the head of the household aged 65 years or over' who are concessional cardholders and who reach the SN receive a quarter of the total government outlay on PBS subsidised medicines. Older single persons who reach the SN under concessional arrangements also receive a high share of all government outlays at 10.6 per cent. Given their annual disposable incomes, government subsidisation of medicines is very significant for these older Australians who require large numbers of scripts per year.

Non-concessional 'couple only families with the family head aged 65 years or over', on average, make the greatest absolute out-of-pocket contribution to the costs of PBS medicines at an estimated $\$ 841$ for the year. This represents 1.6 per cent of their annual disposable income and is second to the relative patient contributions from single general patients aged 65 years or over (2.1 per cent).

\section{Health needs}

Differences in the health characteristics of Australian families underlie these script use and expenditure patterns. Tables 5 and 6 provide information on two basic health indicators - estimated average number of long-term health conditions and average self-assessed health status - for adults in each family type.

Table 5: Health Indicators by Income Quintiles

\begin{tabular}{|c|c|c|c|c|}
\hline & \multicolumn{2}{|c|}{ Families not reaching $S N$} & \multicolumn{2}{|c|}{ Families reaching $S N$} \\
\hline & $\begin{array}{c}\text { Ave. no. long term } \\
\text { health conditions }\end{array}$ & Average SAHS & $\begin{array}{l}\text { Ave. no. long } \\
\text { term health } \\
\text { conditions } \\
\text { dult }\end{array}$ & Average SAHS \\
\hline \multicolumn{5}{|l|}{ Concessional } \\
\hline Bottom 20\% & 2.5 & 2.8 & 5.4 & 3.8 \\
\hline Next $\quad 20 \%$ & 2.5 & 3.1 & 4.7 & 3.6 \\
\hline Middle 20\% & 2.1 & 2.7 & 4.4 & 3.5 \\
\hline Next $\quad 20 \%$ & 2.3 & 2.6 & 5.2 & 3.5 \\
\hline Top $\quad 20 \%$ & 2.3 & 2.5 & 4.8 & 3.3 \\
\hline All & 2.4 & 2.7 & 4.8 & 3.5 \\
\hline \multicolumn{5}{|l|}{ General } \\
\hline Bottom 20\% & 1.5 & 2.3 & 3.3 & 3.2 \\
\hline Next $\quad 20 \%$ & 1.6 & 2.4 & 3.4 & 3.1 \\
\hline Middle 20\% & 1.6 & 2.4 & 3.7 & 3.2 \\
\hline Next $\quad 20 \%$ & 1.6 & 2.2 & 3.2 & 2.8 \\
\hline Top $\quad 20 \%$ & 1.6 & 2.2 & 3.1 & 2.7 \\
\hline All & 1.6 & 2.3 & 3.3 & 3.0 \\
\hline
\end{tabular}

Note: SAHS $=$ self assessed health status on a scale of 1 to 5 where $1=$ excellent and $5=$ poor. 
Table 5 confirms several major health trends: a) the presence of socioeconomic differentials in health with the number of long-term health conditions increasing and self assessed health status decreasing with declining income; b) adults entitled to concessional status have significantly worse health status on average than general patients; and c) the health status of the adults in families reaching the SN is worse than that of adults in families not using large PBS script volumes. The latter two trends also are evident in all of the family types studied (Table 6). Both young and old single adults with concession cards who have high use of PBS medicines appear to do so because they have poor health status. What is concerning is that sole parents with concessional status and whose families reach the SN also have poor health status relative to other Australian adults, averaging 5.2 long-term health conditions each and a self-assessed health status of 3.5 .

Table 6: Health Indicators by Family Type — Lifecycle Group

\begin{tabular}{|c|c|c|c|c|c|c|}
\hline & $\begin{array}{l}\text { Couple with } \\
\text { children }\end{array}$ & $\begin{array}{c}\text { Sole } \\
\text { parent }\end{array}$ & $\begin{array}{l}\text { Couple only, } \\
\text { head }<35 \text { yrs }\end{array}$ & $\begin{array}{l}\text { Couple only, } \\
\text { head } 65+y r s\end{array}$ & $\begin{array}{l}\text { Single Person } \\
<35 \text { yrs }\end{array}$ & $\begin{array}{c}\text { Single Person } \\
65+y r s\end{array}$ \\
\hline & \multicolumn{6}{|c|}{ per adult } \\
\hline \multicolumn{7}{|l|}{ Concessional } \\
\hline \multicolumn{7}{|l|}{ Not-Reaching SN } \\
\hline Ave no. of LT conditions & 1.8 & 1.9 & 1.7 & 2.3 & 1.8 & 3.0 \\
\hline Average SAHS & 2.6 & 2.5 & 2.2 & 2.5 & 2.5 & 2.9 \\
\hline \multicolumn{7}{|l|}{ Reaching SN } \\
\hline Ave no. of LT conditions & 3.4 & 5.2 & 4.0 & 4.3 & 5.1 & 5.8 \\
\hline Average SAHS & 3.6 & 3.5 & 3.2 & 3.4 & 3.9 & 3.6 \\
\hline \multicolumn{7}{|l|}{ General } \\
\hline \multicolumn{7}{|l|}{ Not-Reaching SN } \\
\hline Ave no. of LT conditions & 1.5 & 1.7 & 1.3 & 2.3 & 1.3 & 2.4 \\
\hline Average SAHS & 2.3 & 2.1 & 2.1 & 2.3 & 2.2 & 2.6 \\
\hline \multicolumn{7}{|l|}{ Reaching SN } \\
\hline Ave no. of LT conditions & 2.5 & 2.7 & 2.7 & 3.9 & 4.8 & 4.6 \\
\hline Average SAHS & 2.8 & 2.4 & 2.6 & 3.1 & 2.8 & 3.2 \\
\hline
\end{tabular}

Note: SAHS $=$ self assessed health status on a scale of 1 to 5 where $1=$ excellent and $5=$ poor.

\section{Discussion and Conclusions}

The Government is anticipating saving $\$ 140.3$ million over the next four years by increasing the PBS SN thresholds. With only six months implementation combined with the pattern of use of PBS medicines across the year, the effect of the higher SN arrangements on the distribution of costs between government and consumers is not yet clear. Families typically reach the SN towards the end of a calendar year and it appears that both concessional and general patients 'stocked-up' on PBS medicines before the introduction of the SN budget measure on 1 January 2006 - the proportion of scripts above SN was slightly higher in July-Dec 2005 than the same period in 2004 for both concessional (37.2 vs 36.6 per cent) and general patients (30.2 vs 28.7 per cent) (Medicare Australia, 2006). 
The PBS helps to alleviate the financial pressure faced by many Australian families in accessing prescribed medicines. This modelling has shown that government outlays on the PBS are targeted to low income families, those with concessional status, and elderly couple or elderly single person families with no dependent children. The SN plays an important function in capping costs for many families. Of those concessional families using PBS medicines, one in four are likely to reach the SN threshold while one in ten families without concessional entitlements are likely to. Concessional families who are likely to reach the concessional SN threshold are estimated to receive three-fifths of government outlays on concessional patients while families without concessional status reaching the general patient SN receive two-fifths of government outlays on scripts for general families. The proportion of families expected to reach the SN does vary, however, by income for concessional families, and family typelifecycle group for both concessional and general populations, indicating the presence of some redistributive effects.

Differences in the health characteristics of these groups underlie the script and expenditure patterns reported. There are strong socio-economic and life-cycle differentials in health status with the number of long-term health conditions rising and self-assessed health status declining with decreasing family income and increasing age. The results presented in this paper indicate that the SN is operating as intended. That is, it is supporting families that have relatively poorer health status - at least the adults - and who otherwise may struggle in paying for medicines they need. For these families, government subsidisation of the cost of PBS medicines represents a significant social cash transfer. For a number of concessional family groups, government spending per family equates to in excess of 10 per cent of their annual disposable income.

Changes to the SN arrangements will be felt by these families. For families to reach the SN thresholds, they have had to make the effort to record their use of medicines and keep track of their out of pocket expenditure. Unlike the Medicare safety net, there is no formal method of recording family expenditure on PBS items and whether or not they have reached the PBS SN. Rather, the responsibility for recording patient payments in order to access the SN copayment rates rests with the consumers themselves. This research indicates that there is a strong economic incentive for many Australian families to record their family spending on pharmaceuticals.

As seen in this paper, Government outlays on the PBS are 'pro-poor' and 'pro-sick'. However, families who appear to be least able to afford to pay for medicines themselves and least able to meet such cost-shifting are being asked to generate the proposed savings from the changes to the SN. While for concessional patients, an additional two scripts per year superficially does not seem significant, such a measure potentially could restrict access to medicines and result in some patients not filling their scripts - it has already been seen that the increase in patient copayments in 2005 has reduced demand for PBS subsidised medicines. This could have unintended consequences which could ultimately cost the 
government more than it saves (Donovan, 2002; Harvey 2002; Harvey, 2005). Also as the Pharmacy Guild of Australia (2005) reported:

the new provisions also [will] affect 'general' medicines consumers. For them, the safety net threshold in 2006 will move close to $\$ 1,000$, incorporating the regular CPI increase. This is a significant raising of the bar, and will make it more difficult for families who are sick and need a lot of medicines to reach the safety net.

Models such as MediSim provide policy-makers with decision-support tools that can be used to help evaluate policy options. Testing the distributional impacts of different scenarios based on different SN threshold/co-payment selections, especially within the context of the health outcomes generated from the expenditure on the PBS, would assist in identifying whether or not current investment in the health and well-being of Australian families through the PBS is appropriate or 'optimal' in terms of economic effectiveness, efficiency and social equity. This policy debate will become increasingly pressing with population ageing and rising demand for new medical technologies. The 'artificial' data of MediSim can be usefully combined with real data on drug costs, quality use of medicines and health outcomes, for example, to help inform the debate on the long term affordability and equity of PBS - which up to now has been regarded as one of the best pharmaceutical systems in the world.

\section{References}

Australian Bureau of Statistics (2001), Government Benefits, Taxes and Household Income, Australia, Cat. No. 6537.0, Canberra.

Australian Bureau of Statistics (2003), National Health Survey: User's Guide, 2001, Catalogue No. 4363.0.55.001, Canberra.

Australian Institute of Health and Welfare (2006), Australia's Health, 2006. AIHW Cat. No. 73, Canberra.

ABS-NATSEM Technical Working Group Collaboration on Statistical Matching (2004), 'Statistical Matching of the HES and NHS: An Exploration of Issues in the Use of Unconstrained and Constrained Approaches in Creating a Basefile for a Microsimulation Model of the Pharmaceutical Benefits Scheme', ABS Methodology Advisory Committee Paper, June.

Abello, A., S. Lymer, B. Phillips and A. Harding (2006), 'Enhancing the Australian National Health Survey Data for Use in a Microsimulation Model', paper prepared for the 29th General Conference of the International Association for Research in Income and Wealth, Joensuu, Finland, 20-26 August.

Abello, A., L. Brown, A. Walker and T. Thurecht (2003), 'An Economic Forecasting Microsimulation Model of the Australian Pharmaceutical Benefits Scheme', NATSEM Technical Paper No. 30, University of Canberra. 
Brown, L. and A. Harding (2005), Chapter 10 in Productivity Commission, 'The New Frontier of Health and Aged Care, Quantitative Tools for Microeconomic Policy Analysis', Conference Proceedings (17-18 November, 2004), Canberra.

Brown, L, Abello, A and Harding, A (2005), 'Distributional Impacts of the Pharmaceutical Benefits Scheme's Safety Net', paper presented at the Australian Health Economists' Conference, Auckland, 29-30 September.

Brown, L., A. Abello, B. Phillips and A. Harding (2004), 'Moving Towards an Improved Micro-Simulation Model of the Australian Pharmaceutical Benefits Scheme', Australian Economic Review 37(1):41-61.

Brown, L., A. Abello, B. Phillips and A. Harding (2003), 'The Australian Pharmaceuticals Benefit Scheme and Older Australians: Changes in Government Outlays and Consumer Costs from the 2002-03 Federal Budget Measures', International Microsimulation Conference on Population, Ageing and Health, Canberra, December.

Brown, L. and A. Harding (2002), 'Social Modelling and Public Policy: Application of Microsimulation Modelling in Australia', Journal of Artificial Societies and Social Simulation 5(4), http://jasss.soc.surrey.ac.uk/5/4/6.html.

Creedy, J. (2001), ‘Tax modelling’, Economic Record 77(237):189-202.

Department of Health and Ageing (2005), 'Budget Related Paper No. 1.11' 2005-06 Portfolio Budget Statements, Commonwealth of Australia, Canberra.

Department of Health and Ageing, (2006), http:/www.health.gov.au/internet/wcms/ publishing.nsf/Content/health-pbs-general-pbs-phbensna.htm-copy2.

Department of the Treasury (2005), 'Budget Strategy and Outlook 2005-06', Budget Paper No. 1, Commonwealth of Australia, Canberra.

Department of the Treasury (2005a), 'Expense Measures - Health and Ageing', Budget Paper No 2, Part 2, Commonwealth of Australia, Canberra.

Donovan, J. (2002), 'The Benefits of the PBS to the Australian Community and the Impact of Increased Copayments’, Health Issues 71:1-8.

Harding, A., A. Abello, L., Brown and B. Phillips (2004), 'The Distributional Impact of Government Outlays on the Australian Pharmaceutical Benefits Scheme in 2001-02', Economic Record 80(Special Issue):S83-S96.

Harvey, K. (2002), 'Securing the Future of the Pharmaceutical Benefits Scheme? The Drawing Board', in 'The 2002-03 Federal Budget', An Australian Review of Public Affairs, Symposium, June.

Harvey, K. (2005), 'The Pharmaceutical Benefits Scheme 2003-04', Australia and New Zealand Health Policy 2(1):2-5.

Lymer, S. and L. Brown (2006), 'The Methodological Issues of Using Cross-Sectional Data for Pharmaceutical Health Outcome Analysis’, NATSEM Technical Paper TP31, University of Canberra. 
Medicare Australia (2006), http://www.medicareaustralia.gov.au/providers/health_ statistics/statistical_reporting/pbs.htm.

Pharmacy Guild of Australia (2005), 'Budget Will Add \$327 Million to PBS’, Media Release, Canberra, 10 May.

The construction of the current version of the 'MediSim' model was supported by an Australian Research Council linkage grant (no. LP0219571), and by Medicines Australia, the Industry Partner to this grant. The authors thank Brendan Shaw, Senior Manager, Policy and Research, Medicines Australia and members of the Pharmaceutical Economic Taskforce of Medicines Australia for their advice and input on the modelling, Sharyn Lymer, Senior Research Fellow, NATSEM, for her advice and assistance in the methodological construction of the model, and two anonymous referees for valuable comment. 